\title{
Economic restructuring and sustainable development under the Internet finance mode
}

\author{
Linrui $\mathrm{Fu}^{1}$ \\ ${ }^{1}$ Wuhan University of Technology, Wuhan, China
}

\begin{abstract}
In this information age, the traditional economic mode is shifting towards the Internet finance mode, leading the global economy into an Internet-dominated "new normal". Against this backdrop, Internet finance has brought much convenience to our lives. This study, based on data analysis, made comparisons of economic structures between China and abroad, and between individuals and enterprises, and studied actual cases to introduce the economic restructuring and economic sustainable development in the Internet finance mode.
\end{abstract}

\section{Introduction}

As the national economy in China soars, the economic volume rises year by year, with tectonic changes in the economic structure. As the traditional financial mode moves towards the Internet finance mode, optimizing the economic structure and sustainable development becomes an inevitable trend for high quality economic development in China. Under the Internet finance mode, China's economy registers rapid growth, bringing more convenience to people's life. China, the world's largest developing country, has great impact on the global economy. The Internet finance mode not only leads to reforms on the traditional mode, but provides a fast and advanced platform for global trade. In the age of Internet finance, the economic structure is upgrading, and the sustainable development that features social and ecological integration brought by the new normal is impressive.

\section{Economic restructuring under the Internet finance mode}

The Internet finance mode has six categories: big data finance, P2P online debt, third-party payment, crowdfunding, informatized financial organizations, Internet finance portals. These modes are built on the basis of high tech and supported by digital technology; the elements are allocated in an informatized manner, and based on Internet, economic resources are gathered to integrate virtual imagination with reality, tradition with innovation, and technology with business, to shore up economic growth. The Internet finance mode not only brings about reforms in the industries and trading systems in China and abroad, but leads to changes of individuals and enterprises.

\subsection{Changes caused by Internet finance in China's traditional industrial structure}

There are three traditional industries in China's economic structure. The first is agriculture, referring to the sector that produces food and other bio-materials; the second industry is the manufacturing industry; the third industry cover all those outside the two industries, mainly including the modern service industry and commerce. As Table 1.1 shows, the proportion of the first industry in the national economy from 2015 to 2019 declined year by year, while those of the second and third industries increased steadily, which indicated that the traditional economy is maturing. The monotonous traditional economic structure shows some defects, which can be made up for with the emerging Internet finance mode. For instance, the emerging Internet agriculture uses big data to divert agriculture that belongs to the first industry to the second and third industries, thus changing the proportions of these three industries in the national economy, rising as a new engine for economic progress and promoting rapid growth of GDP 1.

Table1. Proportions of three industries in GDP

\begin{tabular}{|l|l|l|l|l|l|}
\hline & 2015 & 2016 & 2017 & 2018 & 2019 \\
\hline The first industry & $8.4 \%$ & $8.1 \%$ & $7.5 \%$ & $7 \%$ & $7.1 \%$ \\
\hline $\begin{array}{l}\text { The second } \\
\text { industry }\end{array}$ & $38.8 \%$ & $39.6 \%$ & $39.9 \%$ & $39.7 \%$ & $39.0 \%$ \\
\hline The third industry & $50.8 \%$ & $52.4 \%$ & $52.7 \%$ & $53.3 \%$ & $53.9 \%$ \\
\hline
\end{tabular}




\subsection{Changes caused by Internet finance in the global trade system}

Changes in the traditional structure of the global finance legal system are, to some extent, a product of the Internet finance mode. The global finance legal system consists of international financial acts, international financial rules, international finance norms, financial laws concerning foreign affairs, which regulates the global financial order and transactions. However, Internet finance, by virtue of its novel forms, such as virtual space and free financial transactions, changes the traditional global financial system and shapes a new pattern in exploration 2 .

Internet finance also boosts economic globalization, free trading and globalization of production. As the Internet finance gathers momentum, global trading of goods and services increases, which accelerates global trading and free trading. Countries act by following a universal set of standards, making production the fundamental engine of social development and expanding the global market. This is a technological revolution, and with Internet finance as the leading force, it narrows the temporal and spatial gap among countries, accelerates

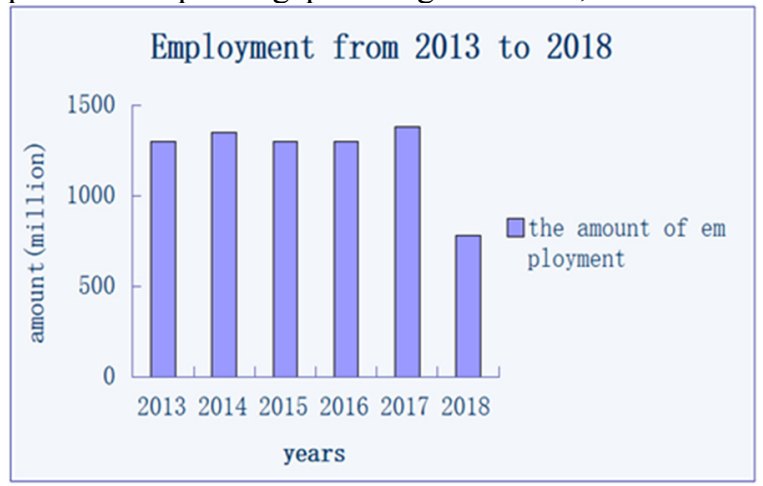

Figure 1 Employment from 2013 to 2018 tectonic shifts in the global trading system and promotes cross-national circulation of production elements. Internet finance calls for cross-boundary cooperation and provides preparation for globalized production, accounting for a fundamental engine of economic globalization.

\subsection{Changes caused by Internet finance in individuals and enterprises}

For individuals, the prevalence of Internet has expanded employment and kept the unemployment rate at a low level. As Figures 1 and 2 show, the jobs in cities during the first half of 2018 increased by $50 \%$, presenting an increasing trend, and the reemployment of the furloughed also enjoyed a great prospect. As Figure 3 shows, since 2013 , the unemployment rate declined steadily to $3.83 \%$ in 2018. The diversified forms of employment are the major reason for the drop in unemployment. Emergence of Internet finance portals, informatized financial institutions and other Internet finance-related organizations expanded the scope of employment, provided timely updating of job information and thus considerably reduced the unemployment rate.

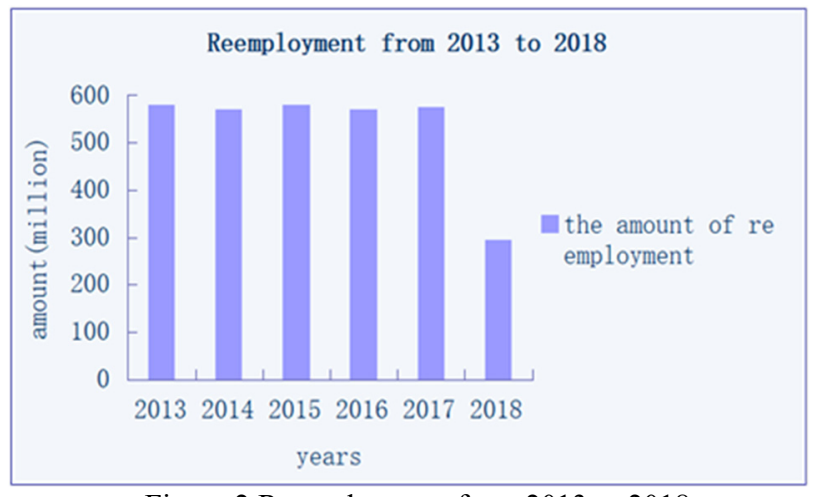

Figure 2 Reemployment from 2013 to 2018

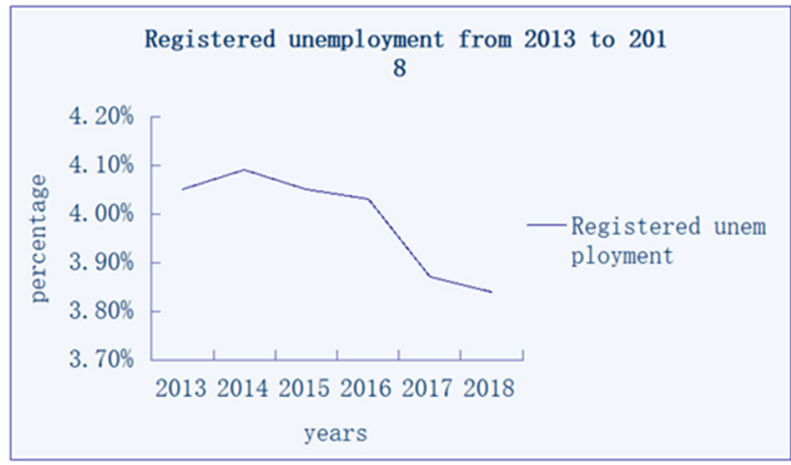

Figure 3 Registered unemployment from 2013 to 2018

For enterprises, the rapid development of Internet technologies, big data technologies and cloud computing gives rise to Internet finance, and supported by both traditional financial departments and Internet finance, different financing channels including stock crowdfunding, P2P online loans, listing on the growth enterprise market, come into being, which causes changes in the financial efficiency, trading structure and even the overall financial framework, and improves the financing environment for startups 3. In summary, the Internet finance mode has brought about tremendous changes to individuals and enterprises: it optimizes the structures, updates information in a more timely manner and makes information more transparent, which are because of the virtues of the Internet. 


\section{Sustainable development under the Internet finance mode}

As the world enters the post-industrialization age, the prevalence of Internet gives birth to a new economic form featured by online consumption. Different from offline consumption, online consumption based on the Internet expanded the channels and scope of consumption, increased the speed of consumption, and to some extent, accelerated the growth of the delivery business, which are manifestations of sustainable development.

\subsection{Internet finance promoting sustainable development of the society}

Internet provides solutions to information sharing and collaboration. New services that Alipay provides in these years including the bus code, online bank, payment of utility bills, hospital appointment all manifest the rise of Internet economy. Internet economy also gives birth to the "sharing economy". This concept was first proposed as a form of "collaborative economy" by Marcus Felson and Joe L. Spaeth, who summarized the three features of this new form of consumption: individuals can have direct trading of commodities and services via third-party platforms 4 . The rise and increasing adoption of shared bikes indicates people's gradual recognition for Internetbased sharing economy. Table 5 shows the changing scales of users of shared bikes in these years. As Figure 4 shows, the number of people using shared bikes saw a gigantic leap from 2016 to 2017, and a steady increase from 2017 to 2018, which manifests people's support for sharing economy and the benefits of this new form of economy to sustainable development.

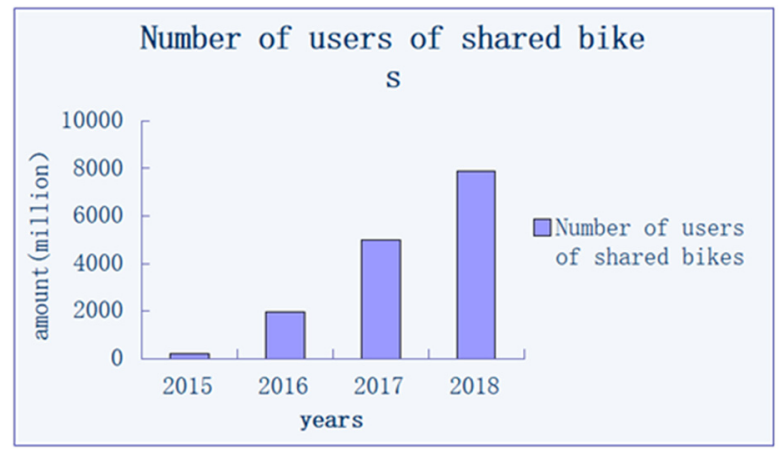

Figure 4 Number of users of shared bikes

\subsection{Internet finance promoting sustainable development of the ecology}

The root cause of economic and social problems is the conflict between the infinite demands of human and the finite supply of natural resources. The emergence of Internet boosts transformation of China's economy from the past industrial economy to an ecologically-friendly and green economy. In the Internet finance mode, all is built on knowledge, and wealth is created by exchange of information, which brings about a new form of economy. Different from traditional industrial production, the new Internet economy saves labor and resources, protects the environment and promotes sustainable development of the ecology 5. From the macroscopic perspective, the emphasis of Internet finance for sustainable development is on reasonable development of natural resources; from the microscopic perspective, Internet finance has built the economic structure for ecological protection and agriculture development under the scheme of sustainable development.

\section{Conclusion}

Analyses above show that the rise of the Internet finance mode has revolutionized the traditional economic structure, adjusted the industrial structure and supplydemand relationship, created novel and diversified economic forms; also, it caused tectonic shifts to the global trading system and made insurmountable contributions to sustainable development of the society and the ecology. For the public, the rise of Internet finance mode has improved people's living standards, reduced the unemployment rate, created new financing channels and brought more convenience to people's daily life. All these have changed the way of life and management and led us to a better Internet era.

\section{References}

1. Wu Wenqing. "Internet $+"$ : New Impetus for Economic Growth and Structural Optimization [J]. China Tendering, 2016, 1264(20):14-15.

2. Li Xuan. A Brief Discussion on the impact of the Development of Internet Finance on international trade [J]. Market Modernization, 2014(33):3-3.

3. Xiong Jie, Pang Jialan. Research on the Mode Selection of Internet Finance supporting Start-up Financing $[\mathrm{J}]$. Modern Economic Information,2019(24):269-271.

4. Chen Ziyao. Thinking on the Sustainable Development of sharing Economy in the Era of "Internet $+" \quad[\mathrm{~J}]$. Cooperative Economy and Technology, 2018(10):36-37.

5. Zhao Junya. Research on sustainable Development of Agricultural Ecological Economy under the New Normal [J]. Agricultural Economy. 2017(3):25-26. 